\title{
ENTRE JOSÉ CASTILLEJO Y JOSÉ M.a ALBAREDA: JULIO PALACIOS, EL «ÚLTIMO PRESIDENTE» DE LA JUNTA PARA AMPLIACIÓN DE ESTUDIOS, 1939-1940
}

\section{Between José Castillejo and José M. ${ }^{a}$ Albareda: Julio Palacios, the "last President» of the Board for Advanced Studies, 1939-1940}

\author{
Rosario E. Fernández Terán y Francisco A. González Redondo \\ Universidad Complutense de Madrid \\ Correo-e: faglezr@edu.ucm.es
}

Recepción: I6 de marzo de 20I5. Envío a informantes: I9 de marzo de 20I5.

Fecha de aceptación definitiva: 20 de enero de 2016

Resumen: Cuando el final de la Guerra Civil se avizoraba inmediato, las nuevas autoridades franquistas encomendaban a Julio Palacios, catedrático de la Universidad Central de Madrid, lo que José M.a Albareda denominaría, en mayo de 1939 , la «misión rectora de nuestra vida científica». En síntesis, la «suprema dirección», con una dedicación análoga a la de José Castillejo antes de la guerra, de los centros que hasta entonces habían pertenecido a la Junta para Ampliación de Estudios (JAE) y a la Fundación Nacional para Investigaciones Científicas (FNICER). Esta tarea de reconstrucción de las instituciones educativas tras la contienda, que llevaría a cabo desde la Vicepresidencia del Instituto de España y hasta que Franco inaugurase el Csic el 28 de octubre de 1940, invita a considerar a Julio Palacios como el «último presidente» de la JAE.

Palabras clave: Julio Palacios; Junta para Ampliación de Estudios; Fundación Nacional para Investigaciones Científicas; Instituto de España; Consejo Superior de Investigaciones Científicas.

Aвstract: As the end of Spanish Civil War was assumed as definitive, the new Francoist authorities commissioned Julio Palacios, Professor at Madrid's Central 
ENTRE JOSÉ CASTILLEJO Y JOSÉ M. a ALBAREDA: JULIO PALACIOS, EL «ÚLTIMO PRESIDENTE» DE LA JUNTA PARA AMPLIACIÓN DE ESTUDIOS, I939-I940 ROSARIO E. FERNÁNDEZ TERÁN Y FRANCISCO A. GONZÁLEZ REDONDO

University, what José M. Albareda would describe in May 1939 as the «governing mission of Spanish Science». In other words, the "supreme directorship», which resembles José Castillejo's dedication before the war, of all those institutes belonging until then to the Board for Advanced Studies (JAE) and the National Foundation for Scientific Research (FNICER). His efforts towards the reconstruction of the educational institutions after the conflict, undertaken from his position as Vice-president of the Institute of Spain, and until Franco inaugurated the CSIC on $28^{\text {th }}$ October 1940, suggest that Palacios could be considered the «last President» of the JAE.

Key words: Julio Palacios; Board for Advanced Studies; National Foundation for Scientific Research; Institute of Spain; Higher Council for Scientific Research.

\section{A modo de presentación}

$\mathrm{E}$

N eSte TRABajo se estudia el final de la Junta para Ampliación de Estudios e Investigaciones Cientificas (JAE) en el marco de la construcción del Estado franquista tras la Guerra Civil, una nueva España que entendía la JAE como la principal obra de la Institución Libre de Enseñanza (ILE), considerada por los vencedores en la contienda, precisamente, como culpable de la «tragedia de España» ${ }^{\mathrm{I}}$.

$Y$ es que, cuando se habla de la ILE, se está haciendo referencia a cuatro cosas, relacionadas entre sí, pero distintas. En primer lugar, se alude a la idea alumbrada en I876 por un pequeño grupo de catedráticos expedientados por no querer someter sus enseñanzas a los dogmas imperantes (entre ellos, Francisco Giner de los Ríos, Gumersindo de Azcárate, Nicolás Salmerón y Augusto González de Linares): la idea de crear una Universidad privada a la altura de su tiempo, al margen de las anquilosadas universidades oficiales de la época. También se evoca, en segundo lugar, el Colegio de primera y segunda enseñanzas, con ese nombre de Institución Libre de Enseñanza, en el que finalmente pudo concretarse en I88I la idea inicial, una vez reintegrados en sus puestos los catedráticos sancionados y abandonadas unas incipientes enseñanzas de nivel universitario. Y, sobre todo, en tercer lugar, se intenta resumir en una expresión única un conjunto de sentimientos patrióticos, un espíritu de regeneración de España que empezaba a concretarse en I876, el institucionismo, que buscaba la solución a siglos de decadencia en la europeización, entendida ésta como fundamento de la innovación educativa y de la incorporación a las corrientes científicas de los países más avanzados de nuestro entorno ${ }^{2}$.

Entre las referencias especialmente significativas sobre este tema se encuentran: SUÑ̃R, E.: Los intelectuales y la tragedia de España, Burgos, Editorial Española, I937. vv. AA.: Una poderosa fuerza secreta. La Institución Libre de Enseñanza, San Sebastián, Editorial Española, 1940. Puede verse también GonzÁlez Redondo, F. A.: «Cultura i Ciència durant la República: de la generació del 76 a la generació del 27», en Escrivá MosCardó, C. (ed.): Converses sobre el Llegat cultural de la República, Valencia, Societat Coral El Micalet, 2015, pp. 92-I2I.

2 Puede verse la obra ya clásica de Jiménez-LANDI, A.: La Institución Libre de Enseñanza y su ambiente, 4 tomos, Madrid, Editorial Complutense, 1996. 
ENTRE JOSÉ CASTILlEJO Y JOSÉ M. a ALBAREDA: JULIO PALACIOS, EL «ÚLTIMO PRESIDENTE» DE LA JUNTA PARA AMPLIACIÓN DE ESTUDIOS, I939-I940 ROSARIO E. FERNÁNDEZ TERÁN Y FRANCISCO A. GONZÁLEZ REDONDO

Pero, en cuarto lugar, lo que se quería que hubiera sido, trascendiendo considerablemente lo que realmente fue y, sobre todo, materializando el espíritu reformador que emanaban los institucionistas, se concretó en 1907 en un organismo inspirado por la ILE, dirigido por personas íntimamente relacionadas con ella, como Castillejo, su secretario y alma mater (también por Cajal, su presidente), pero claramente distinta: la Junta para Ampliación de Estudios; un completo entramado universitario de nivel internacional, pero formalmente independiente de todas las Universidades del Reino y con prácticamente absoluta autonomía para gestionar los fondos que el Estado le proporcionaba; todo ello encaminado a la búsqueda de una definitiva convergencia de España con Europa en materia educativa y científica.

Las figuras de Castillejo y Cajal al frente de la JAE han sido bastante estudiadas. También lo ha sido Ignacio Bolívar, presidente a partir de 1934, al fallecer Cajal . Pero, con seguridad, quedan muchos estudios por realizar en torno al papel jugado por Ramón Prieto Bances, secretario de la JAE al hacerse cargo Castillejo de la Fundación Nacional para Investigaciones Científicas y Ensayos de Reformas (FNICER) en I9354, la complicada labor de Manuel Márquez y Tomás Navarro Tomás dirigiendo la Junta desde su Comisión Delegada en Valencia y Barcelona durante la guerra civils... así como la presidencia-secretaría de Julio Palacios en I939 y hasta bien avanzado 1940, cuando se puso en marcha el CsIC sobre las cenizas de la JAE, período que se estudiará en este trabajo.

Julio Palacios Martínez, nacido en Paniza (Zaragoza) en I89i, en el seno de una familia culta, muy conservadora y decididamente católica ${ }^{6}$, estudió el Bachillerato en el Instituto de la capital oscense, quedando a cargo de su tío, el obispo de Huesca. En 1907 comenzó sus estudios de Ciencias en Zaragoza, que continuó en la Universidad de Barcelona, donde terminaría las Licenciaturas de Ciencias Físicas y Ciencias Exactas.

En I9II, recomendado por su maestro en Barcelona, Esteban Terradas, se presentó ante Blas Cabrera en el Laboratorio de Investigaciones Físicas de la JAE, bajo cuya tutela, mientras realizaba el Servicio Militar a las órdenes de Alfonso de Orleans en el Regimiento del Rey (punto de partida de su relación con la Casa Real), completó la tesis doctoral leída en I9I4 y entró en I9I5 como profesor auxiliar de Termología en la Facultad de Ciencias. A los pocos meses, en abril de i9i6, con 25 años recién cumplidos, obtuvo por oposición la Cátedra de Termología de la Universidad Central.

Gomis Blanco, A.: «El compromiso de Ignacio Bolívar con la JaE», en Sánchez Ron, J. M. y García-Velasco, J. (coords.): ioo Jae. La Junta para Ampliación de Estudios e Investigaciones Científicas en su centenario, Madrid, Residencia de Estudiantes, 20IO, pp. 232-255.

4 Formentín Ibáñez, J. y Rodríguez Fraile, E.: La Fundación Nacional para Investigaciones Científicas (I931-1939). Actas del Consejo de Administración y Estudio Preliminar, Madrid, csic, 200I.

Su labor puede seguirse, por ejemplo, a partir del Libro de Actas de la Comisión Delegada (Valencia y Barcelona), Archivo de la Residencia de Estudiantes, Madrid.

6 Para la reconstrucción de la biografía científica de Palacios pueden verse: GonzÁlez DE PosADA, F.: Julio Palacios: físico español, aragonés ilustre, Madrid, Amigos de la Cultura Científica, I994; y González de Posada, F.: «Julio Palacios Martínez», en Grandes vidas de la España de nuestro tiempo. 3. Física, Madrid, Editorial Universitaria Ramón Areces, 2008, pp. 93-I46. 
ENTRE JOSÉ CASTILLEJO Y JOSÉ M. a ALBAREDA: JULIO PALACIOS, EL «ÚLTIMO PRESIDENTE» DE LA JUNTA PARA AMPLIACIÓN DE ESTUDIOS, I939-I940 ROSARIO E. FERNÁNDEZ TERÁN Y FRANCISCO A. GONZÁLEZ REDONDO

Decidido a aprender las técnicas de bajas temperaturas que necesitaba su maestro Cabrera y no tenía en el Laboratorio de Madrid, ese mismo año de I9I6, en medio de la I Guerra Mundial, viajaría a Leiden (Holanda) pensionado por la JAE, para trabajar en el Laboratorio de Criogenia con H. Kammerlingh Onnes y C. A. Cromelin. Al finalizar la guerra se integró como jefe de Sección en el Laboratorio de Investigaciones Físicas. Completando sus trabajos experimentales, durante el curso 1922-1923 participó activamente en las sesiones preparatorias de la venida de Einstein en la Sociedad Matemática Española.

Notoriamente ya monárquico y católico, fue colaborador científico en el periódico El Debate dirigido por Ángel Herrera Oria. Designado vocal de la JAE en 1926 por Primo de Rivera, en 1927 fue seleccionado para formar parte de la Junta Constructora de la Ciudad Universitaria de Madrid en los terrenos de La Moncloa cedidos por Alfonso XIII. Finalmente, elegido presidente de la Sociedad Española de Física y Química, logró en 1928 que el monarca le otorgase el título de «Real» que ostentan hoy las Sociedades de Física y de Química. Con la llegada de la República se relacionó, activo y militante, con el partido Acción Nacional (luego con Renovación Española y la CEDA) y la revista Acción Española, mientras colaboraba en las tareas científicas dirigidas por Blas Cabrera, como jefe de la Sección de Rayos X del Instituto Nacional de Física y Química. Entre sus muchos cargos, fue miembro del Patronato de la Universidad Internacional de Verano en Santander, embajador cultural español de la Junta de Relaciones Culturales del Ministerio de Estado en Filipinas durante el «bienio negro», etc.

Palacios permaneció en Madrid durante toda la Guerra Civil, protegido por su hermano, Miguel Palacios, comandante médico del $5 .^{\circ}$ Regimiento, con el objetivo confesado de poder protegerlo cuando las tropas nacionales entrasen en Madrid, algo que siempre vio claro en el horizonte. De hecho, fue quintacolumnista de Franco en el Madrid sitiado, y jugó un papel significativo en el proceso negociador hacia una «paz honrosa» con Segismundo Casado y Julián Besteiro, como agente del simp nacional entre febrero y marzo de $1939^{7}$.

En suma, la vida de Palacios proporciona numerosos temas de estudio relevantes para la Historia de la Educación en España. Algunos, como su Dirección de la «Cátedra Cajal» de la Institución Cultural Española de Buenos Aires, gestionada por la JAE en Madrid, se han publicado ya en las páginas de esta revista8. El que nos ocupa ahora es, como se avanzaba arriba, su papel como «último presidente» de la JAE. Documentémoslo con detalle.

Palacios, J.: «Datos acerca de la liberación de Madrid en I939», Síntesis, año xIv, n. ${ }^{\circ}$ I66 (I959), pp. IO-I6.

8 Puede verse: Fernández Terán, R. E. y González Redondo, F. A.: «Las cátedras de la Institución Cultural Española de Buenos Aires. Ciencia y Educación entre Argentina y España», Historia de la Educación, vol. 29 (2010), pp. 195-219. 
ENTRE JOSÉ CASTILLEJO Y JOSÉ M. a ALBAREDA: JULIO PALACIOS, EL «ÚLTIMO PRESIDENTE» DE LA JUNTA PARA AMPLIACIÓN DE ESTUDIOS, I939-I940 ROSARIO E. FERNÁNDEZ TERÁN Y FRANCISCO A. GONZÁLEZ REDONDO

\section{La JAE ante las «dos Españas» en Guerra Civil, I936-1939}

El Is de septiembre de 1936, Jesús Hernández Tomás, ministro de Instrucción Pública y Bellas Artes de la República, firmaba un Decreto por el que quedaban «disueltas todas las Academias dependientes del Ministerio», en concreto, la Academia de la Historia, la Academia de Bellas Artes de San Fernando, la Academia de Ciencias Exactas, Físicas y Naturales, la Academia de Ciencias Morales y Políticas y la Academia Nacional de Medicina», dando vida, para sustituirlas, al Instituto Nacional de Cultura9.

En el proceso de organización del bando nacional y aprovechando este vacío institucional creado por las autoridades republicanas, el 8 de diciembre de 1937 Franco sancionaba en Burgos un Decreto por el que «en homenaje a la veneranda tradición española de colocar la vida doctoral bajo los auspicios de la Inmaculada Concepción de María», se escogía ese día «para proceder a la convocatoria de las Reales Academias de España, cuyas tareas se encuentran desde hace tiempo interrumpidas y cuyo renacer es con impaciencia esperado en la España nacional» ${ }^{10}$.

En el artículo primero del Decreto se disponía que el 6 de enero de 1938 «se reunirán en sesión solemne» las Academias, que recuperarían el título de Reales, «y formarán, juntas, un cuerpo total con el nombre de Instituto de España». La organización y atribuciones de este Instituto quedarían definidas por el Decreto firmado por Franco el i9 de mayo de 1938 , que disponía en su artículo primero ${ }^{\text {It: }}$

El Instituto de España, además del carácter corporativo de Senado de la Cultura Patria, será el órgano a través del cual el Estado orientará y dirigirá la alta Cultura y la investigación superior en España, viniendo a sustituir, en parte, a la Junta de Ampliaciones de Estudios y Pensiones para el Extranjero (sic).

Esta idea se extendía en el artículo segundo, donde se adelantaba que en órdenes sucesivas se determinaría qué centros debían pasar a depender del Instituto, así como las «partes o servicios de los mismos, que habiendo pertenecido hasta ahora a la Junta para Ampliación de Estudios, deban ser entregados para su continuación a las Universidades españolas». Es verdad que el artículo séptimo decretaba que quedaba «disuelta la Junta para Ampliación de Estudios», pero en la primavera de 1938 los centros y el personal de la Junta, radicados en Madrid, Valencia y Barcelona, seguían dependiendo no de la España Nacional, sino del Gobierno de la República ${ }^{12}$.

9 Gaceta de Madrid, n. ${ }^{\circ}$ 26I, I7 de septiembre de 1936, pp. I857-I858. Las referencias a la creación y primeros pasos del Instituto de España que se analizan en este apartado pueden seguirse también, aunque con las debidas prevenciones dadas las lagunas en cuanto a fechas y los errores en la trascripción de los sucesivos Decretos, en Calvo-Sotelo, J.: «Instituto de España», en Las Reales Academias del Instituto de España, Madrid, Alianza Editorial, 1992, pp. 19-49.

1o Decreto n. ${ }^{\circ} 427, B O E$, n. $^{\circ} 4 \mathrm{I} 4,8$ de diciembre de I937, p. $47 \mathrm{I} 4$.

"I $B O E$, n. $^{\circ} 576,20$ de mayo de 1938 , pp. 7418-7419.

12 Un denso análisis de esta «doble realidad» de la JAE puede consultarse en FERnández Terán, R. E.: El profesorado del Instituto Nacional de Física y Química ante la Guerra Civil, el proceso de 
ENTRE JOSÉ CASTILLEJO Y JOSÉ M. a ALBAREDA: JULIO PALACIOS, EL «ÚLTIMO PRESIDENTE» DE LA JUNTA PARA AMPLIACIÓN DE ESTUDIOS, I939-I940 ROSARIO E. FERNÁNDEZ TERÁN Y FRANCISCO A. GONZÁLEZ REDONDO

De hecho, el 23 de junio de 1936 había celebrado la JAE su última sesión antes de que, entre el I7 y el i8 de julio, el intento de golpe de Estado militar acabase convertido en guerra civil. Habían delegado entonces el despacho de todos los asuntos urgentes durante el verano en la Comisión ejecutiva, aunque ésta no se reuniría hasta el 24 de agosto ${ }^{13}$, con la asistencia únicamente de Ignacio Bolívar (presidente), Ramón Menéndez Pidal, Manuel Márquez, Teófilo Hernando y Gregorio Marañón ${ }^{14}$. El primer punto tratado en la misma fue la renuncia al cargo del secretario (y sucesor de José Castillejo) Ramón Prieto Bances, y la propuesta para la vacante de Tomás Navarro Tomás, quien actuaría desde ese mismo día como secretario accidental. También se señalaron algunas propuestas de modificación que afectaban a la estructura de los Centros de la JAE ${ }^{15}$, quedando establecida a partir de esa fecha la nueva clasificación de las actividades de la Junta en tres secciones ${ }^{16}$ : Ampliación de estudios, Centro de Estudios Históricos y Centro de Estudios Cientificos.

La primera sección integraba las pensiones y delegaciones, las relaciones con el extranjero (cambio de repetidores, asociación para el socorro de la Ciencia alemana, Fundación universitaria de Bruselas, Instituto de las Españas, relación con la Sociedad de Naciones, etc.) y las instituciones de carácter educativo (Instituto Escuela, Residencia de Estudiantes y sus Laboratorios, Centros de profesores extranjeros en España y cursos de vacaciones y trimestrales para extranjeros).

Las secciones comprendidas en el Centro de Estudios Históricos serían las de Filología española (Historia de la lengua lexicográfica. Laboratorio de fonética. Atlas lingüístico), Instituto de Estudios Clásicos, Archivo de la palabra, Estudios Hispano Americanos, Instituto de Estudios Medievales, Estudios de Arqueología, Estudios de Arte Pictórico, Estudios de Arte Escultórico y Fichero Artístico Español.

depuración y el drama del exilio, tesis doctoral, Facultad de Educación, Universidad Complutense de Madrid, 20I4.

${ }_{13}$ Unas primeras referencias a este período de la jaE se avanzaron en FERnÁNdez TERÁn, R. E. y González Redondo, F. A.: «Blas Cabrera y la Física en España durante la Segunda República», Llull. Revista de la Sociedad Española de Historia de las Ciencias y de las Técnicas, vol. 30 (2007), pp. 65-IO3. Más en concreto, puede verse también Fernández Terán, R. E.: «Les cendres científiques de la República: de la Junta per Ampliació d’Estudis al CsIC», en Escrivá Moscardó, C. (ed.): Converses sobre el Llegat cultural de la República, Valencia, Societat Coral El Micalet, 20I5, pp. 42-75.

${ }^{14}$ Sesión del 24 de agosto. Libro de Actas de la Junta, tomo viII, p. I47. Archivo de la JAE. Residencia de Estudiantes, Madrid. A esta sesión se hace referencia en Fernández Terán, R. E. y GonzÁlez Redondo, F. A.: «La Junta para Ampliación de Estudios e Investigaciones Científicas en el Centenario de su creación», Revista Complutense de Educación, vol. I8 (2007), pp. 13-34. Puede verse, también, Sánchez Ron, J. M.: Cincel, martillo y piedra: historia de la ciencia en España (siglos XIX Y XX), Madrid, Taurus, I999, p. 303.

is Esta reorganización durante la Guerra no se detalla en las obras colectivas: PUIG-SAmper, Mulero, M. A. (ed.): Tiempos de investigación. JAE-CSIC, cien años de ciencia en España, Madrid, CSIC, 2007; VIÑAO, A. (coord.): Reformas e innovaciones educativas (España, 1907-1939). Número Extraordinario de Revista de Educación, Madrid, 2007; vv. AA.: En el centenario de la Junta para Ampliación de Estudios (1907-2007). Número monográfico del Boletín de la Institución Libre de Enseñanza, Madrid, n. ${ }^{\circ}$ 63-64, 2007; etc.

${ }_{16}$ Sesión del 26 de agosto de 1936, Libro de Actas de la Junta, tomo viII, pp. I5I-I52. 
ENTRE JOSÉ CASTILlEJO Y JOSÉ M. a ALBAREDA: JULIO PALACIOS, EL «ÚLTIMO PRESIDENTE» DE LA JUNTA PARA AMPLIACIÓN DE ESTUDIOS, I939-I940 ROSARIO E. FERNÁNDEZ TERÁN Y FRANCISCO A. GONZÁLEZ REDONDO

Por último, el Centro de Estudios Científicos englobaría los ya tradicionales Instituto Nacional de Ciencias Naturales (Museo Nacional de Ciencias Naturales, Museo de Antropología y Jardín Botánico), Instituto Cajal, Misión Biológica de Galicia, Instituto Nacional de Física y Quimica, Laboratorio de Histología Normal y Patológica, Laboratorio de Fisiología y Seminario Matemático.

El I9 de diciembre de $1936^{17}$, como continuación de las medidas de evacuación de Madrid del Gobierno y de las dependencias ministeriales emprendidas en noviembre, se decidía también el traslado de la Junta a Valencia constituyendo una Comisión Delegada provisional, con Manuel Márquez como presidente, y con José Moreno Villa y Victorio Macho como vocales, continuando como secretario Tomás Navarro Tomás y Luis A. Santullano como vicesecretario.

En la capital republicana todo estaba preparado para recibirles, como manifestaba el secretario en la sesión de constitución de la Comisión ${ }^{18}$. La tarea más urgente era ${ }^{19}$ «normalizar en lo posible las actividades de la Junta y recoger las de los colaboradores de sus Centros y de otros investigadores que se hayan visto obligados a interrumpir sus trabajos y se hallen en situación de continuarlos», por lo que se acordó «examinar el estado presente de los diferentes servicios de la Junta y del personal adscrito a ellas».

Transcurrido otro medio año, en el que continuaron las actividades de los centros de la JAE ${ }^{20}$, en la sesión del 9 de agosto de 1937 se leía una Orden del 4 de agosto por la que se encargaba a la Comisión Delegada la misión de «velar por que no se interrumpan las labores de estudio e investigaciones encomendadas a los diversos centros dependientes de la Junta» haciendo todo lo que fuera necesario «por que estas labores se intensifiquen en cuanto lo aconsejen las circunstancias actuales». En cumplimiento de este encargo se distribuían las delegaciones de la Comisión en los centros de la JAE del modo siguiente ${ }^{21}$ : Manuel Márquez (Instituto Cajal, Laboratorio de Histología y trabajos de Neuropatología y Hematología), José Puche (Instituto [Nacional] de Física y Química, Laboratorio de Quimica, Seminario Matemático y Laboratorio de Metalografía), Márquez y Puche (Laboratorio de Fisiología y publicaciones de la Junta de carácter científico), Victorio Macho (Residencia de Estudiantes «de varones y femenina»), José M. ${ }^{a}$ Ots (Centro de Estudios Históricos), Antonio Machado (Publicaciones de carácter literario) y Manuel Sánchez Arcas (Museo Nacional de Ciencias Naturales).

Por otro lado, si desde enero de 1937 la Comisión Delegada se había tenido que hacer cargo de varios laboratorios dependientes de la Fundación Nacional para

17 Gaceta de la República, n. ${ }^{\circ}$ 355, 20 de diciembre de 1936, pp. I055-1056.

18 Sesión del 22 de diciembre de 1936. Libro de Actas de la Comisión Delegada (Valencia), pp. I-2. A este traslado se hace referencia también en SÁnchez Ron, J. M.: «La Junta para Ampliación de Estudios e Investigaciones Científicas (1907-2007)», en SÁnchez Ron, J. M. et al. (eds.): El laboratorio de España. La Junta para Ampliación de Estudios e Investigaciones Científicas (1907-1939), Madrid, Publicaciones de la Residencia de Estudiantes, 2007, pp. 67-I25.

19 Sesión del 22 de diciembre de 1936, Libro de Actas de la Comisión Delegada (Valencia), pp. I-2.

20 Sesión del 9 de agosto de 1937, Libro de Actas de la Comisión Delegada (Valencia), p. 43.

${ }_{21}$ Sesión del 9 de agosto de 1937, Libro de Actas de la Comisión Delegada (Valencia), p. 44. 
ENTRE JOSÉ CASTILLEJO Y JOSÉ M. a ALBAREDA: JULIO PALACIOS, EL «ÚLTIMO PRESIDENTE» DE LA JUNTA PARA AMPLIACIÓN DE ESTUDIOS, I939-I940 ROSARIO E. FERNÁNDEZ TERÁN Y FRANCISCO A. GONZÁLEZ REDONDO

Investigaciones Cientificas, otra Orden de 13 de agosto determinaba que debían pasar a depender de la JAE los centros activos en la zona republicana de la FNICER, "por haber sido suspendidas en los momentos actuales las actividades de otros centros de dicha institución», acordando la Comisión «rogar al Ministerio señale las condiciones económicas en que ha de cumplirse el encargo» ${ }^{22}$.

En suma, como parece obvio ${ }^{23}$, la JAE (en general, el Gobierno republicano) no asumió lo decretado por Franco al crear el Instituto de España en 1937-1938, y mantendría sus actividades durante la contienda, de modo que el Centro de Estudios Históricos, el Laboratorio de Investigaciones Biológicas, el Instituto Nacional de Física y Química, varios de los centros de la Fundación Nacional para Investigaciones Cientificas, etc., seguirían existiendo realmente (no se habrían «disuelto») durante la guerra civil.

De hecho, la propia España franquista así parecía entenderlo cuando, el mismo día de «la liberación» de Madrid por las fuerzas nacionales, el catedrático de Termología de la Facultad de Ciencias de Madrid, Julio Palacios Martínez, quedaría «nombrado accidentalmente, Encargado del Instituto Nacional de Física y Química»"24, tal como le comunicaba, el 29 de marzo de 1939, "III Año Triunfal», el jefe de los Servicios de Orden Público en Madrid, desde la Jefatura del simp, en el Estado Mayor del Ejército del Centro, firmando «por orden» Antonio Bouthelier, miembro del Servicio de Información Militar y Policía (simp) de Franco.

Dos días después, el 30 de marzo, el jefe del Estado firmaba un Decreto por el cual ${ }^{25}$ : A propuesta del Ministro de Educación Nacional y previa deliberación del Consejo de Ministros, vengo en nombrar Vicerrector de la Universidad de Madrid a don Julio Palacios Martínez, Catedrático de la misma», mientras el I4 de abril, tal como Eugenio d'Ors le comunicaría desde San Sebastián ${ }^{26}$, «la Mesa del Instituto de España acordó que, en vista de los méritos y circunstancias que en V.E. concurren, fuese designado para formar parte como Presidente del Patronato del Instituto Nacional de Física y Química», centro cuya organización y régimen competerían al Instituto de España, según Decreto de 26 de abril de 1939 .

Ese mismo 26 de abril, un día antes de que Franco rubricase su cese como ministro de Educación Nacional27, Sainz Rodríguez firmaría la designación de

${ }_{22}$ Sesión del 4 de septiembre de 1937, Libro de Actas de la Comisión Delegada (Valencia), pp. 50-51.

23 Esta perspectiva no aparece contemplada en algunos autores, que dan por terminada la JAE con los Decretos franquistas de 1937 y 1938. Puede verse, por ejemplo, Sánchez Ron, J. M.: «La Junta para Ampliación de Estudios e Investigaciones Científicas ochenta años después», en SÁnchez Ron, J. M. (ed.): 1907-1987. La Junta para Ampliación de Estudios e Investigaciones Científicas 80 años después, Madrid, Consejo Superior de Investigaciones Científicas, 1988, pp. I-6I. Para este autor, a partir de 1937 «no hubo ya labor ni para la JAE como institución, ni para sus hombres como pensadores».

${ }_{24}$ Archivo Julio Palacios, Caja D2.

25 Expediente personal de Julio Palacios. AGA, Sección de Educación, Legajo 32/I5052.

26 Archivo Julio Palacios, Caja D8.

${ }_{27}$ Decreto de la Jefatura del Estado de 27 de abril de 1939, publicado en el $B O E$, n. $^{\circ}$ II 8,28 de abril de 1939, p. 2276. 
ENTRE JOSÉ CASTILLEJO Y JOSÉ M. a ALBAREDA: JULIO PALACIOS, EL «ÚLTIMO PRESIDENTE» DE LA JUNTA PARA AMPLIACIÓN DE ESTUDIOS, I939-I940 ROSARIO E. FERNÁNDEZ TERÁN Y FRANCISCO A. GONZÁLEZ REDONDO

Palacios como vicepresidente del Instituto de España $a^{28}$, el cargo más relevante de todos los que recibiría. En efecto, aunque Manuel de Falla había sido nombrado presidente del Instituto tras su creación, ausente del país el músico gaditano y encontrándose enfermo desde antes de que empezara la Guerra Civil, el I8 de junio de 1938 el ministro Sainz Rodríguez había firmado una Orden Ministerial por la que se concedía que Falla siguiese ostentando formalmente la Presidencia, aunque se le «exime de toda función directiva aneja al cargo ${ }^{29}$. Para resolver el vacío en el organigrama directivo, en la Orden se explicitaba que «hasta tanto que, restablecido en su salud, estime conveniente volver al ejercicio de su función, se confieren todas sus atribuciones al Vicepresidente del Instituto de España», cargo que, si en 1938 ocupaba únicamente Sainz Rodríguez, a partir de ese 26 de abril de 1939, también recaería en Julio Palacios, tal como él mismo explicaba ${ }^{30}$ :

Terminada la guerra, fui nombrado Vicerrector de la Universidad de Madrid y Vicepresidente del Instituto de España. Este último cargo me hacía responsable de la reorganización de las Reales Academias y de todo cuanto dependía de la Junta para Ampliación de Estudios e Investigaciones Científicas, pues el Presidente del Instituto, el gran músico Falla, residía en la Argentina y nunca tomó posesión de su cargo.

El cargo de vicepresidente del Instituto conllevaría una mayor responsabilidad que el anterior de vicerrector, pues excedía el ámbito de la vida estrictamente universitaria e investigadora y alcanzaba al conjunto de actividades, funciones y organismos que habían sido responsabilidad de la JAE. Así, el i de mayo de I939, desde el Ministerio de Educación Nacional se comunicaba a Palacios, a través del subsecretario de ese Departamento, Alfonso García Valdecasas (responsable de la gestión ministerial desde el cese de Sainz Rodríguez), su nombramiento como «supremo director $»^{31}$ :

Para lograr más rápidamente la normalidad de los Centros de alta investigación científica residentes en Madrid, así como para la selección del personal afecto a los mismos, este Ministerio ha dispuesto:

I $^{\circ}$. Conferir al Excmo. Sr. D. Julio Palacios Martínez, en calidad de Vicepresidente del Instituto de España y Vicerrector de la Universidad Central, la suprema dirección de todos los centros de Ciencias Físico-matemáticas y naturales dependientes de este Ministerio, establecidos en Madrid.

${ }_{28}$ Nombramiento propuesto por Sainz Rodríguez y publicado en el $B O E, \mathrm{n} .^{\circ}{ }_{11} 8,28$ de abril de 1939, p. 2278, un día después de su cese como ministro de Educación Nacional. Referencias a los cargos recibidos por Palacios con naturaleza de «Vice» pueden verse en GonzÁlez DE PosadA: $o p$. cit., 1994 y 2008.

${ }_{29} B O E, \mathrm{n} .^{\circ} 609,23$ de junio de $1938, \mathrm{p} .7983$.

30 Archivo Julio Palacios, Caja D7. «Currículum Vitae» escrito en 1969.

${ }^{31} \quad$ Archivo de la Residencia de Estudiantes, Caja 8530, Carpeta 4. Una parte de los contenidos de esta caja ha sido citada, desde otras perspectivas, por MALET, A.: «Las primeras décadas del csic: Investigación y ciencia para el franquismo», en Romero, A. y SANTESmases, M. J. (eds.): Un siglo de política cientifica en España, Madrid, Fundación BBvA, 2008, pp. 2II-256. 
ENTRE JOSÉ CASTILLEJO Y JOSÉ M. a ALBAREDA: JULIO PALACIOS, EL «ÚLTIMO PRESIDENTE» DE LA JUNTA PARA AMPLIACIÓN DE ESTUDIOS, I939-I940 ROSARIO E. FERNÁNDEZ TERÁN Y FRANCISCO A. GONZÁLEZ REDONDO

$2^{\circ}$. Facultarle para la adopción de cuantas medidas de urgencia estime necesarias, las cuales pondrá en conocimiento de este Ministerio y para la propuesta al mismo de los nombramientos de Directores de los Centros a que se refiere el apartado anterior.

La situación que se encontró Palacios en esos momentos quedaría descrita por el ministro de Educación Nacional que había concebido todos esos nombramientos antes de su propio cese, Pedro Sainz Rodríguez, en una carta que le envió éste desde Lisboa el 25 de marzo de $1958^{32}$ :

Mi querido amigo: una ligera indisposición me impide asistir al homenaje que se le tributa, pero no quiero dejar de expresar mi adhesión con la presente carta que le ruego sea leída en ese acto. No es de ahora mi profunda estimación por la persona y la obra científica de Julio Palacios. Cuando tuve en mi mano la posibilidad de hacerlo le designé para los más altos puestos directivos de la enseñanza y la investigación en el campo de las ciencias a que sus especialidades pertenecen.

Pero, quizá, la manifestación más clara de la realidad de Palacios en aquellos momentos se encuentre en un párrafo contenido en la carta que le mandó desde Vitoria quien meses después sería designado secretario del csic, José María Albareda, el 4 de mayo de 1939, carta en la que le relataba su salida de la España republicana por Andorra en $1937^{33}$ : «Deseaba felicitarle, además, por su misión rectora de nuestra vida científica. Aún más que Ud. es ésta la que está de enhorabuena». Comenzaba, de hecho, esa etapa final, breve pero intensa, de la Junta para Ampliación de Estudios (y de la Fundación Nacional para Investigaciones Cientificas), que terminaría con su disolución por integración en el Consejo Superior de Investigaciones Cientificas. En este sentido, por la «misión rectora» que le había sido encomendada, en mayo de r939 Julio Palacios puede ser considerado el «último presidente» de la Junta para Ampliación de Estudios. Veámoslo todo con cierto detalle.

\section{La «misión rectora» del «Supremo Director» de la JAE}

La tarea reorganizadora de Julio Palacios al frente de las instituciones que antes habían sido dirigidas desde la JAE se iniciaría tan pronto como recibió las atribuciones correspondientes. Así, sin pérdida de tiempo, el día 4 de mayo decidía ${ }^{34}$ :

32 Archivo Julio Palacios, Caja D2. Esta carta y la siguiente de José M. ${ }^{a}$ Albareda se hicieron públicas por primera vez en: González Redondo, F. A.: «La reorganización de la Matemática en España tras la Guerra Civil. La posibilitación del retorno de Esteban Terradas y Julio Rey Pastor», La Gaceta de la Real Sociedad Matemática Española, vol. 5 (2002), pp. 463-49o. El análisis se completó en: González Redondo, F. A.; Fernández Terán, R. E. y González Redondo, A.: «El papel de Julio Palacios en la reorganización de la Ciencia española tras la Guerra Civil», en Actas del IV Simposio "Ciencia y Técnica en España de 1898 a 1945: Cabrera, Cajal, Torres Quevedo", Madrid, Amigos de la Cultura Científica, 2004, pp. I09-130. Tomadas las cartas de estos trabajos, posteriormente las citó y analizó MALET: op. cit., 2008.

33 Archivo Julio Palacios, Caja D2. Ver nota anterior.

34 Archivo de la Residencia de Estudiantes, Caja 8530, Carpeta 23. 
ENTRE JOSÉ CASTILLEJO Y JOSÉ M. a ALBAREDA: JULIO PALACIOS, EL «ÚLTIMO PRESIDENTE» DE LA JUNTA PARA AMPLIACIÓN DE ESTUDIOS, I939-I940 ROSARIO E. FERNÁNDEZ TERÁN Y FRANCISCO A. GONZÁLEZ REDONDO

Esta Vicepresidencia ha dispuesto nombrar Director provisional del Laboratorio de estudios biológicos al Catedrático excedente de la Facultad de Medicina D. José María del Corral García, el cual queda facultado para hacerse cargo de edificios y cuanto en ellos se contenga, donde estuvo instalado el Instituto Cajal y los laboratorios que regentaban los Sres. Del Río Ortega y Negrín, procediendo a la depuración del personal de dichos Centros, proponiendo a esta Vicepresidencia lo que corresponda en cada caso.

Y en lo referente al funcionamiento de la estructura administrativa de la JAE, el 6 de mayo comunicaba al ministro de Educación Nacional (por acumulación de esta cartera a la suya propia de Justicia, tras el cese de Sainz Rodríguez), Tomás Domínguez Arévalo, conde de Rodezno ${ }^{35}$ :

Esta Vicepresidencia ha acordado que el Secretario provisional de la Vicepresidencia de este Instituto, D. Juan de la Cierva López, se haga cargo de los locales donde estaba establecida la antigua Junta de Ampliación de Estudios (sic), instalando en los mismos las Oficinas dependientes del Instituto y tomando las disposiciones precisas para que puedan ser utilizados los locales en la función científica a que se destina; realizando el inventario de los documentos que existan en los mismos e informando y proponiendo a esta Vicepresidencia de cuanto estime necesario.

Ese mismo día 6 de mayo Palacios nombraba «con carácter de urgencia Directora Provisional de la Residencia de Señoritas», en tanto que institución «dependiente de la disuelta Junta para Ampliación de Estudios, a D. ${ }^{a}$ Eulalia Lapresta Rodríguez, para que se haga cargo de los locales de la expresada Residencia», y para que haga la «depuración del personal, informando a esta Vicepresidencia de la reorganización y medidas urgentes que sean necesarias para el funcionamiento de dicho Centro» ${ }^{36}$. En otra carta fechada ese mismo día nombraba a Francisco Donato Prunera director provisional de la Residencia de Estudiantes de la calle del Pinar n. ${ }^{\circ}$ I, con las funciones de «hacerse cargo de los locales», que habían sido ocupados por las fuerzas militares, «proceder a su limpieza y llevar a cabo la depuración del personal» ${ }^{37}$.

Análogamente, ese día 6 de mayo nombraba «Director Provisional del Centro de Estudios filosóficos y matemáticos» al catedrático de Matemáticas de la Universidad Central, Francisco de Asís Navarro Borrás, «el cual se hará cargo de los servicios de índole análoga a los de dicho Centro organizados por la disuelta Junta para Ampliación de Estudios» ${ }^{38}$.

Otros centros de la Junta también se verían afectados por los nuevos nombramientos y la impaciencia en pro de la reorganización que caracterizaban las

Archivo de la Residencia de Estudiantes, Caja 8530, Carpeta 4.

Archivo de la Residencia de Estudiantes, Caja 8530, Carpeta 8.

Archivo de la Residencia de Estudiantes, Caja 8530, Carpeta 8.

${ }_{38}$ Archivo de la Residencia de Estudiantes, Caja 8530, Carpeta 8. Este centro sería heredero del Laboratorio y Seminario Matemático que puso en marcha Julio Rey Pastor en I9Is y que durante la Guerra había estado dirigido por José Barinaga Mata. 
ENTRE JOSÉ CASTILLEJO Y JOSÉ M. a ALBAREDA: JULIO PALACIOS, EL «ÚLTIMO PRESIDENTE» DE LA JUNTA PARA AMPLIACIÓN DE ESTUDIOS, I939-I940 ROSARIO E. FERNÁNDEZ TERÁN Y FRANCISCO A. GONZÁLEZ REDONDO

primeras medidas, "con carácter de urgencia», tomadas por Julio Palacios en el uso de las atribuciones que le fueron conferidas por la Orden del i de mayo referida más arriba. Así, en sendos escritos firmados el i2 de mayo, designaría director provisional del Museo Antropológico a Francisco de las Barras de Aragón e, igualmente, director provisional del Jardín Botánico al también catedrático de la Sección de Ciencias Naturales de la Facultad de Ciencias de Madrid, Arturo Caballero Segares, ambos con la misión de hacerse cargo de cada centro y proponer «cuantas medidas estime convenientes para su conservación y desenvolvimiento» ${ }^{39}$.

Un día más tarde, el iz de mayo, encargaba al jefe de Sección y secretario del Instituto Nacional de Física y Química, Julio Guzmán Carrancio, «de todo lo relacionado con el IX Congreso de Quimica pura y aplicada, a fin de que informe sobre el estado de cuentas del mismo y proponga el medio de llegar a su liquidación» ${ }^{\circ}$.

El i6 de mayo, y con las mismas finalidades que los anteriores nombramientos, Palacios nombraba director provisional del Museo Nacional de Ciencias Naturales a Pedro de Novo F. Chicharro, y director provisional del Centro de Estudios Históricos al catedrático de Instituto Miguel Herrero García ${ }^{4 \mathrm{I}}$.

Y se sucedían los nombramientos realizados por Palacios desde el momento en que asumió la dirección de los antiguos centros de la Junta. Así, el 23 de mayo, encargaba al general de Brigada Juan López Soler poner en marcha la organización de la Sociedad Matemática Española y presentar un informe del estado de la Sociedad ${ }^{42}$; y el 26, en escrito dirigido al director de la Misión Biológica de Galicia, escribía ${ }^{43}$ :

Disuelta la antigua Junta para Ampliación de Estudios e Investigaciones Científicas, de la que dependía esa misión, la cual pasa actualmente a depender de este Instituto, de acuerdo con el Decreto de 19 de mayo de 1938, ruégole remita a la mayor brevedad posible a esta Vicepresidencia informe sobre la situación actual y desenvolvimiento de este Centro para ponerlo en conocimiento de la mesa de este Instituto.

Pero no todo iba a ser fácil en las tareas de renovación tomadas por el «Supremo Director» de lo que había sido y seguía siendo la Junta, y en las nuevas circunstancias habría que solventar muchas cuestiones. Así, en un telegrama oficial enviado por Julio Palacios el 24 de mayo al subsecretario de Educación Nacional, le informaba que ese mismo día, por la tarde, se había presentado el delegado del

39 Archivo de la Residencia de Estudiantes, Caja 8530, Carpeta 8.

Archivo de la Residencia de Estudiantes, Caja 8530, Carpeta 4.

Archivo de la Residencia de Estudiantes, Caja 8530, Carpeta 8.

42 Archivo de la Residencia de Estudiantes, Caja 8530, Carpeta 8. Este episodio concreto se estudia en González Redondo, F. A. (ed.): «Mirando hacia atrás. Sociedad Matemática Española. Estado de la misma en el mes de junio de 1939", La Gaceta de la Real Sociedad Matemática Española, vol. I4 (20II), pp. 773-790.

${ }_{43}$ Archivo de la Residencia de Estudiantes, Caja 8530, Carpeta 4. 
ENTRE JOSÉ CASTILlEJO Y JOSÉ M. a ALBAREDA: JULIO PALACIOS, EL «ÚLTIMO PRESIDENTE» DE LA JUNTA PARA AMPLIACIÓN DE ESTUDIOS, I939-I940 ROSARIO E. FERNÁNDEZ TERÁN Y FRANCISCO A. GONZÁLEZ REDONDO

gobernador civil con intención de incautarse el edificio del Centro de Estudios Históricos, dependiente también de Palacios desde su Vicepresidencia del Instituto de España. Le rogaba que recabase del ministro de la Gobernación la suspensión de la incautación «hasta ser oído el Instituto de España y evitar mayores males a la cultura española» ${ }^{44}$. Igualmente, enviaba al día siguiente otro telegrama al ministro de Educación Nacional, Tomás Domínguez Arévalo, informándole de que en el edificio sito en Medinaceli 4 funcionaban «las bibliotecas, los seminarios y los laboratorios en los que trabajan los Sres. Herreros, Ballesteros, Pabón, Entrambasaguas, Santa-Olalla, entre otros» ${ }^{45}$.

La solución que adoptaría Palacios para solventar la cuestión de la incautación del edificio del Centro de Estudios Históricos de la calle Medinaceli sería el traslado de las oficinas de la antigua JAe al edificio del Instituto Nacional de Física y Quimica, sito en la calle Serrano ing (y que, como se apuntaba antes, estaba bajo su dirección desde el final de la guerra), donde seguiría prestando los servicios que tenía encomendados. Así, el i7 de junio daba la orden «para remitir a la nueva oficina las máquinas de escribir y el material que estime imprescindible» ${ }^{46}$.

Después de la urgente designación de los cargos de confianza en cuyas manos ponía la dirección de los mismos centros que habían dependido de la Junta, se hacía preciso conocer de qué personal disponían y qué cargos ocupaban, en un exhaustivo afán de reorganización y control que caracterizaba la España del momento. Con este objetivo, el 20 de junio Palacios dirigía una orden a cada uno de los centros que ahora dependían directamente de él, solicitando «la relación de personal directivo y colaborador de ese Centro, en la que consten los cargos que ostentan y los méritos científicos que tenga, con objeto de que consten en su expediente personal» ${ }^{47}$. Estos centros, en transcripción literal, eran:

Instituto de Estudios Internacionales y Económicos, Museo Nacional de Ciencias Naturales, Junta para Ampliación de Estudios ${ }^{48}$, Centro de Estudios Matemáticos, Residencia de Estudiantes, Museo de Antropología, Laboratorio de Estudios Biológicos, Jardín Botánico, Centro de Investigaciones Vinícolas, Centro de Estudios Históricos, Comisión de Adquisición de material científico, Residencia de Señoritas, Instituto Nacional de Física y Química.

Y es que Palacios no sólo se había convertido en el «último presidente» de la JAE. Como vicepresidente del Instituto de España, por el artículo 6 del Decreto de 26 de abril de 1939, también le correspondería convertirse en el «último presidente» de la Fundación Nacional para Investigaciones Científicas y Ensayos de Reforma ${ }^{49}$, institución de la que José Castillejo había sido administrador general

\footnotetext{
Archivo de la Residencia de Estudiantes, Caja 8530, Carpeta 8.

Archivo de la Residencia de Estudiantes, Caja 8530, Carpeta 8.

Archivo de la Residencia de Estudiantes, Caja 8530, Carpeta 5.

Archivo de la Residencia de Estudiantes, Caja 8530, Carpeta 5.

${ }^{8}$ Aparece así, tachado, en el original.

49 En general, sobre la FNICER, pueden consultarse: Formentín IbÁÑEZ y Rodríguez FraiLE: op. cit., 20oI, y López, S.: «Las ciencias aplicadas y las técnicas: la Fundación Nacional de Investigaciones
} 
ENTRE JOSÉ CASTILLEJO Y JOSÉ M. a ALBAREDA: JULIO PALACIOS, EL «ÚLTIMO PRESIDENTE» DE LA JUNTA PARA AMPLIACIÓN DE ESTUDIOS, I939-I940 ROSARIO E. FERNÁNDEZ TERÁN Y FRANCISCO A. GONZÁLEZ REDONDO

hasta el comienzo de la Guerra Civil. Así, el i3 de mayo de 1939 desde la Vicepresidencia del Instituto se tomaba la siguiente decisión ${ }^{50}$ :

Esta Vicepresidencia ha dispuesto, con carácter de urgencia, nombrar Director provisional del Instituto de Estudios internacionales y económicos, dependiente de la antigua Fundación Nacional para investigaciones y ensayos de reforma, al Catedrático de Universidad, D. Antonio Luna García, el cual procederá a hacerse cargo de los servicios y locales del expresado Centro y depuración de su personal, proponiendo a esta Vicepresidencia las medidas que estime convenientes para la conservación y desenvolvimiento de dicho Instituto.

La dirección de la FNICER implicaba recabar información de los diferentes centros que habían dependido de ella y de la situación en la que se encontraban los mismos tras la guerra ${ }^{51}$. Una de las tareas prioritarias consistía en determinar qué laboratorios formaban parte de ese entramado institucional y qué tipo de actividades venían desempeñando. En este sentido escribía Palacios a su amigo y antiguo compañero, el catedrático de Química en la Facultad de Ciencias de Valencia, Antonio Ipíens, el 24 de mayo de $1939^{52}$ :

Me han informado de que durante la etapa roja la Junta para Ampliación estableció en Valencia un laboratorio de metalografía, el cual estaba dirigido por D. José Navarro Alcácer. Yo le agradecería a Vd. muchísimo me informara sobre la labor de dicho laboratorio, si sería interesante o no el sostenerlo y cuantos detalles o informes estime necesarios para mi conocimiento.

También me han informado de que en la Universidad de Valencia ha quedado un depósito de material, muebles, libros y una máquina de escribir Hispano-Olivetti n. ${ }^{\circ} 42588$, perteneciente a la disuelta Junta para Ampliación de Estudios. También sobre este asunto le agradecería a Vd. que me informara.

El 27 de junio recibía la respuesta directamente de Navarro Alcácer, en la que éste adelantaba que «con esta fecha he escrito al Instituto de España sobre mis tareas metalográficas. Como quizá Vd. tenga que informar sobre ello, me ha parecido un deber participárselo y agradecerle de antemano el interés que Vd. pueda dispensar a estas labores» ${ }^{3}$.

El 26 de mayo de 1939 Palacios escribía al director del Laboratorio de Histología y Cultivo de Tejidos (en la Universidad de Valladolid) y al director del

Científicas y Ensayos de Reformas y el Patronato Juan de la Cierva del Csic (I93I-I96I)», en Romero, A. y Santesmases, M. J. (eds.): Un siglo de política científica en España, Madrid, Fundación BBva, 2008, pp. 79-106.

so Archivo de la residencia de Estudiantes, Caja 8530, Carpeta 3.

${ }_{51}$ Acerca de las tareas de reorganización de la FNICER por Palacios puede verse: FeRNÁndeZ Terán, R. E.: «Las cendres científiques de la República: de la Junta per Ampliació d’Estudis al csic», en Escrivá, C. y Maestre, R. (eds.): Converses sobre el Llegat Cultural de la República, Valencia, Societat Coral el Micalet, 20I5, pp. 42-75.

${ }_{52}$ Archivo de la Residencia de Estudiantes, Caja 8530, Carpeta 4.

53 Archivo de la Residencia de Estudiantes, Caja 8530, Carpeta 4. 
ENTRE JOSÉ CASTILLEJO Y JOSÉ M. a ALBAREDA: JULIO PALACIOS, EL «ÚLTIMO PRESIDENTE» DE LA JUNTA PARA AMPLIACIÓN DE ESTUDIOS, I939-I940 ROSARIO E. FERNÁNDEZ TERÁN Y FRANCISCO A. GONZÁLEZ REDONDO

Laboratorio de Química Orgánica (en la Universidad de Salamanca), todos ellos dependientes de la FNICER, solicitando informes «sobre la situación actual y desenvolvimiento de ese Laboratorio a esta Vicepresidencia, para a su vez informar ésta sobre dichos extremos a la Mesa de este Instituto" ${ }^{54}$. Y, complementariamente, en una extensa carta del 7 de junio, el catedrático de Química de la Universidad de Zaragoza, Antonio de Gregorio Rocasolano, exponía a Palacios sus pretensiones con respecto al Laboratorio de Investigaciones Bioquímicas, una vez conocido el acuerdo del Instituto de España de instalar en Zaragoza el «Seminario Bioquímico» y de nombrarle director del mismoss:

$\mathrm{El}$ «Seminario Bioquímico» que continuará la labor del Laboratorio de Investigaciones Bioquimicas que fundé y dirijo en la Facultad de Ciencias de Zaragoza, podría complementar su actuación realizando trabajos de Química aplicada a la Industria que en relación con la Facultad de Ciencias tiene en Zaragoza una tradición que interesaría al país fomentar.

Si se acepta por el Instituto de España la adición o complemento que proponemos, el Centro de alta cultura a organizar en Zaragoza podría ser un «Seminario Bioquímico y de Química aplicada» que podría desde luego establecerse y laborar en el actual Laboratorio de Investigaciones Bioquímicas» de la Facultad de Ciencias de Zaragoza, con la ampliación de local posible.

En suma, tal como continuaba escribiendo Palacios en el currículum vitae que se transcribía parcialmente antes ${ }^{6}:$ «Con los escasos elementos disponibles y siguiendo las normas de austeridad de la antigua Junta, logré poner en marcha todos sus Institutos de investigación». Es decir, había procedido a una reorganización que permitiera la dirección y el control de todos ellos, ahora bajo la dependencia orgánica del Instituto y su propia «presidencia», y manteniendo todos los nombres y la estructura que tenían en la JAE y en la FNICER, continuidad que se podría retrotraer, incluso, a la obra de la Institución Libre de Enseñanza, por la cual, como se documentará más adelante, se le pasaria la correspondiente factura.

Pero Palacios no solamente tendría el control académico de las instituciones; en sus manos recaería también el control económico de todos los centros, tal como se documenta expresamente a partir de una carta de «El Vicepresidente en funciones de Presidente», del I7 de junio, dirigida al ministro de Educación Nacionals7:

Las partidas presupuestarias que al Instituto de España corresponden, son todas las que pertenecían a la disuelta Junta para Ampliación de Estudios y a la Fundación Nacional de Investigaciones Científicas, las cuales se han fundido en el Instituto por expresa designación de la legislación mencionada.

Si en toda labor es peligrosa la solución de continuidad, no escapará a la clara inteligencia de v.E. que en el Instituto de España podría producir efectos de desastre.

\footnotetext{
Archivo de la Residencia de Estudiantes, Caja 8530, Carpeta 4.

Archivo Julio Palacios, Caja Diz.

Archivo Julio Palacios, Caja $\mathrm{D}_{7}$.

Archivo de la Residencia de Estudiantes, Caja 8530, Carpeta 8.
} 
ENTRE JOSÉ CASTILLEJO Y JOSÉ M. a ALBAREDA: JULIO PALACIOS, EL «ÚLTIMO PRESIDENTE» DE LA JUNTA PARA AMPLIACIÓN DE ESTUDIOS, I939-I940 ROSARIO E. FERNÁNDEZ TERÁN Y FRANCISCO A. GONZÁLEZ REDONDO

En efecto, el Instituto de España acordó, en su sesión del i4 de junio, que le fuesen libradas a esa institución y a nombre de su habilitado, D. José M. ${ }^{a}$ García Baamonde de la Cuesta, las cantidades consignadas en los presupuestos generales del Estado. Y en la sesión de la Mesa del Instituto, celebrada el día 29 de junio de 1939, "tomó el acuerdo de designar al Vicepresidente D. Julio Palacios y Martínez y al Tesorero D. Agustín González de Amezúa y Mayo» para que fuesen los que llevasen «la firma para el movimiento de la cuenta corriente del Instituto de España en el Banco del Río de la Plata de Londres», mientras en otro escrito similar de la misma fecha se tomó idéntico acuerdo para que ambos «lleven la firma para el movimiento de la cuenta corriente del Instituto de España en el Banco Hispano Americano de Madrid» ${ }^{8}$, según certificaba el secretario perpetuo de la institución, Eugenio D’Ors y Rovira, con diligencias firmadas el 30 de junio.

El 5 de julio de 1939 Palacios ordenaba a los respectivos directores a los que había nombrado «redactar los Reglamentos de los Centros que de él dependían». Lo explicaba en los siguientes términos ${ }^{\varsigma}$ : "Para que presida el mayor acierto en su confección, entiendo que deben ser hechas propuestas de Reglamento particulares por los Directores respectivos». A modo de guía les acompañaba una copia de el del Instituto Nacional de Física y Química, «rogando que se inspire en él respecto a toda la organización general, con objeto de que guarden todos los Reglamentos cierta uniformidad, aunque naturalmente con las modificaciones peculiares que a cada centro interesen». Y solicitaba el proyecto de Reglamento de cada uno de los centros a la mayor brevedad posible.

A la vuelta del verano, el 6 de septiembre de 1939, el vicepresidente del Instituto «en funciones de Presidente», trasladaba al ministro de Educación Nacional (entonces ya José Ibáñez Martín) el estado en que se encontraba el proceso de reorganización emprendido ${ }^{60}$ :

Para que puedan darse las órdenes que pongan a disposición del Instituto de España los créditos consignados en el Presupuesto del Estado para la desaparecida Junta para Ampliación de Estudios, la Fundación Nacional de Investigaciones Científicas y todos los otros atribuidos a distintos centros hoy dependientes del Instituto de España en virtud de los decretos del I9 de mayo de 1938 y 26 de abril de 1939, adjunto remito los indicados presupuestos, debiendo hacerle observar a v.E. la imposibilidad de una determinación más detallada por tratarse en algunos casos de Centros que empiezan a actuar por primera vez en este año, $y$, por tanto, hasta el próximo con pleno conocimiento de sus actividades y gastos, es imposible mayor detalle.

58 Archivo de la Residencia de Estudiantes, Caja 8530, Carpeta 6.

59 En la lista de centros ya no figuran la Residencia de Estudiantes, ni la Residencia de Señoritas. Aparece tachado el Laboratorio de Estudios Biológicos y se incluye, sustituyendo a éste, el Instituto Cajal. Archivo de la Residencia de Estudiantes, Caja 8530, Carpeta 5.

60 Archivo de la Residencia de Estudiantes, Caja 8530, Carpeta 3. 
ENTRE JOSÉ CASTILLEJO Y JOSÉ M. a ALBAREDA: JULIO PALACIOS, EL «ÚLTIMO PRESIDENTE» DE LA JUNTA PARA AMPLIACIÓN DE ESTUDIOS, I939-I940 ROSARIO E. FERNÁNDEZ TERÁN Y FRANCISCO A. GONZÁLEZ REDONDO

\section{Primeros problemas en la «misión rectora» de Palacios}

El «papel rector» de Palacios como «último presidente» de la JAE, transcurridos los primeros meses desde el fin de la guerra, no había estado exento de dificultades y desencuentros. No le afectó especialmente el proceso «formal» de depuración establecido en la Ley de io de febrero de $1939^{61}$, por el que todos los funcionarios estaban obligados a presentar ante la Jefatura Provincial o Ministerio correspondiente una solicitud de reingreso al cuerpo, acompañada de una declaración jurada que iba a ser sometida a prueba mediante los distintos informes y testimonios recabados por las comisiones de depuración.

Así, entregada la solicitud por el interesado en el Juzgado Militar de Funcionarios, y presentada la declaración jurada correspondiente, desde el Juzgado se solicitaba el in de abril de 1939 al jefe del simp «certificación de la conducta político-social, anterior y posterior al is de julio, referida al funcionario D. Julio Palacios Martínez» ${ }^{62}$. Y el iz de abril se emitía la certificación presentando a éste como «persona de orden y afecta al ideario de s.E. el generalísimo Franco», perteneciente «desde su fundación a Unión Monárquica, Acción Popular, T.Y.R.E., Acción Española y Bloque Nacional Antimarxista y se manifestó contrario al Frente Popular». En otro informe simultáneo del I3 de abril, avalado por el jefe provincial de FET y JONS se testificaban los mismos datos. Además se especificaba que era agente del simp desde enero de $1939^{63}$.

Como cabía esperar, el juez instructor designado para la depuración del personal docente de la Universidad de Madrid, Enríquez de Salamanca, propuso el Is de julio la «admisión al servicio activo sin imposición de sanción» de Palacios (junto a Luis Bermejo Vida y Ricardo San Juan Llosa, también catedráticos de la misma Facultad) $)^{64}$. El final del proceso de depuración, pura formalidad en este caso, llegó con la Orden ministerial del 27 de julio de 1939, que decidía el reingreso en la cátedra de Termología de la Facultad de Ciencias de Madrid ${ }^{65}$.

Pero en el mes de junio de ese año 1939, Palacios había sido parcialmente desautorizado por las autoridades ministeriales por algunas de las medidas adoptadas en la reorganización de las dependencias de la JAE. Así, el jefe del Servicio Nacional de Enseñanza Superior y Media, José Pemartín, comunicaba al vicepresidente del

6 Ley de io de febrero de 1939 «fijando normas para la depuración de funcionarios políticos», $B O E$, n. $^{\circ}$ 45, I4 de febrero de i939, pp. 856-859. Pueden verse: González Redondo, F. A. y Villanueva VAldÉs, M. A.: «La depuración de los científicos españoles entre 1936 y 1939. Un caso de estudio: Blas Cabrera Felipe», Llull, 24 (200I), pp. 685-704; GonzÁlez Roldán, G.: El nacimiento de la Universidad franquista: la depuración republicana y franquista de los Catedráticos de universidad, tesis doctoral, Facultad de Geografía e Historia, UNED, 20oI, etc.

62 Expediente personal de Julio Palacios, AGA, legajo 32/15052.

${ }_{63}$ Expediente personal de Julio Palacios, AGA, legajo 32/15052. Sobre el papel de Palacios en las filas del simp, como quintacolumnista de Franco en el Madrid sitiado de la Guerra Civil, puede verse Fernández Terán: op. cit., 20I4. También Cervera, J.: Madrid en guerra. La ciudad clandestina. Madrid, Alianza, I999.

${ }_{64}$ Expediente personal de Julio Palacios, AGA, legajo 32/I5052.

65 Expediente personal de Julio Palacios, AGA, legajo 32/15052. 
ENTRE JOSÉ CASTILLEJO Y JOSÉ M. a ALBAREDA: JULIO PALACIOS, EL «ÚLTIMO PRESIDENTE» DE LA JUNTA PARA AMPLIACIÓN DE ESTUDIOS, I939-I940 ROSARIO E. FERNÁNDEZ TERÁN Y FRANCISCO A. GONZÁLEZ REDONDO

Instituto de España el acuerdo adoptado por el ministro de Educación Nacional en funciones, Tomás Domínguez Arévalo, el 7 de junio ${ }^{66}$ :

La apertura inmediata de las Universidades exige la urgente reorganización de aquellos Organismos que más puedan favorecer su alta función docente y suplir muy perentorias necesidades de la clase escolar. Por ello, este Ministerio, considerando que las instalaciones de las Residencias de Estudiantes y de Señoritas de Madrid constituyen la base de aquellos Organismos, cuya organización técnica cae bajo la jurisdicción de la Jefatura del Servicio Nacional de Enseñanza Superior y Media, ha dispuesto que esta proceda inmediatamente a la reorganización de dichos Centros y a las designaciones personales que para ello entienda convenientes.

La inmediata normalización de la vida docente en Madrid obliga a adoptar con el mayor cuidado medidas varias entre las cuales aparece apremiante la de reorganizar la Residencia de Estudiantes y la de Señoritas de aquella capital. A tal efecto, este Ministerio ha resuelto nombrar una Comisión compuesta por las siguientes personas: Presidente: D. Fernando Enríquez de Salamanca y Dánvila, Catedrático de la Universidad de Madrid; Vocales: D. Francisco Cantera, Catedrático de la Universidad de Madrid, D. Francisco Navarro Borrás, Catedrático del mismo Centro, D. José María Albareda Herrera, Director del Instituto «Ramiro de Maeztu», $\mathrm{D}^{\mathrm{a}}$ Julia Ochoa, Secretaria del Museo Pedagógico, $\mathrm{D}^{\mathrm{a}}$ Victoria Grau, Doctora en Filosofía y Letras, D ${ }^{a}$ Emma Álvarez, Doctora en Medicina, D. Mario González Pons, Director de la Residencia de Estudiantes y Da María Díaz Jiménez, Directora de la Residencia de Señoritas.

Realmente, Alfonso García Valdecasas, subsecretario del Ministerio de Educación, ya le había adelantado la nueva situación a Palacios el 2 de junio ${ }^{67}$, primero «ratificando los nombramientos hechos para los Centros de Ciencias Naturales y Matemáticas», «la adscripción de La Cierva» y «las designaciones de Luna y Herrero»; pero también destacándole que «el Ministro había nombrado, respectivamente, a Don Mario González Pons y a Da María Díaz Jiménez, a propuesta del Sr. Pemartín», como directores de las Residencia de Estudiantes y de Señoritas, rectificación de los nombramientos que él había realizado (y que no habían llegado a recogerse en el $B O E$ ), por los que se veía obligado a disculparse por escrito ante García Valdecasas el i2 de junio ${ }^{68}$ :

Mi distinguido Jefe y querido amigo: He recibido la suya fecha 2 del cte. y los nombramientos que en ella me anunciaba.

Me preocupa mucho que pueda $\mathrm{Vd}$. pensar que haya habido extralimitación por mi parte. Crea Vd. que no ha sido nunca ésa mi intención y que todos los nombramientos que hice fueron pensando en la necesidad que había para bien de nuestra Patria de poner en movimiento todos los centros dependientes del Instituto de España. Pero si usted cree que tal extralimitación tuvo lugar, discúlpeme en gracia a la intención. Debo advertirle que la designación del Sr. Luna no me creí autorizado a

66 Archivo de la Residencia de Estudiantes, Caja 8530, Carpeta 4.

${ }_{67}$ Archivo Julio Palacios, Caja Di3.

68 Archivo de la Residencia de Estudiantes, Caja 8530, Carpeta 4. 
ENTRE JOSÉ CASTILLEJO Y JOSÉ M. a ALBAREDA: JULIO PALACIOS, EL «ÚLTIMO PRESIDENTE» DE LA JUNTA PARA AMPLIACIÓN DE ESTUDIOS, I939-I940 ROSARIO E. FERNÁNDEZ TERÁN Y FRANCISCO A. GONZÁLEZ REDONDO

hacerla por la Orden del I ${ }^{\circ}$ de Mayo, sino por pertenecer el Centro a la Fundación Nacional y ser esta dependiente del Instituto por el Decreto del 26 de abril de 1939 que en el artículo $6^{\circ}$ dice que todos los organismos dependientes de la Fundación Nacional quedarán a cargo del Instituto de España.

Disculpas análogas presentaba, ese mismo I2 de junio, ante José Pemartín ${ }^{69}$ :

Mi distinguido amigo: Recibo la suya fecha 7 de junio corriente en la que se anuncia la designación por el Ministerio de nuevos Directores de las Residencias de Estudiantes y Señoritas, de Madrid. Le ruego me disculpe si entiende que hubo extralimitación en ello; pero yo me permito hacerle observar que si hice los nombramientos de Directores provisionales de ambos establecimientos, no fue por la orden de $\mathrm{I}^{\circ}$ de Mayo, sino por entender que ambos dependían del Instituto de España porque expresamente lo dispone el artículo $6^{\circ}$ del D. de 26 de Abril de 1939, al adscribir al Instituto todos los organismos dependientes antes de la Junta para Ampliación de Estudios y no haberse determinado por el Ministerio, de acuerdo con el artículo $2^{\text {a }}$ del D. de 19 de Mayo de 1938, cosa distinta. Vds. sin embargo, con su superior criterio resolverán lo que estimen más procedente y mejor para el desenvolvimiento de la cultura nacional.

Todas las tareas de reorganización al frente de la JAE y la FNICER las estaba realizando en un contexto muy complicado, y recibiendo muchas presiones. Por ejemplo, Enrique Herrera, desde la Federación de Amigos de la Enseñanza «Atenas», le había escrito el i de junio en tanto que «Querido amigo en Xto» ${ }^{\circ}$, sugiriéndole algunos nombramientos «que caerían muy bien en la opinión pública preocupada, como Vd. sabe, porque elementos afines a la Institución Libre de Enseñanza ocupen otra vez los cargos de los centros de cultura». La respuesta de Palacios no se hizo esperar, y el 3 de junio le contestaba:

Hay en su carta un párrafo que me ha llenado de alarma; el referente a que elementos afines a la Institución Libre [de Enseñanza] ocupan otra vez cargos en los centros de cultura. Considero esto sumamente grave, y creo que es necesario, en conciencia, aclarar concretamente cuáles sean estos casos, para evitar que puestos directivos y de influencia en nuestra orientación cultural caigan en manos indeseables. Todo lo más que podemos tolerar es que tales elementos trabajen donde realmente sean útiles y no constituyan ningún peligro.

La percepción que se tenía en la Nueva España de Palacios como continuador de la obra de la ILE permearía en los centros de decisión del nuevo Régimen, como se explicitará más adelante, pero en esos momentos de 1939 el físico aragonés estaba ocupado ultimando los preparativos de su viaje cultural a Argentina, el cual había quedado pendiente tras la sublevación militar del i8 de julio de $1936^{71}$.

69 Archivo de la Residencia de Estudiantes, Caja 8530, Carpeta 4.

- Archivo Julio Palacios, Caja D3.

71 A estas cuestiones ya nos hemos referido en Fernández Terán y González Redondo: op. cit., 2010. 
ENTRE JOSÉ CASTILLEJO Y JOSÉ M. a ALBAREDA: JULIO PALACIOS, EL «ÚLTIMO PRESIDENTE» DE LA JUNTA PARA AMPLIACIÓN DE ESTUDIOS, I939-I940 ROSARIO E. FERNÁNDEZ TERÁN Y FRANCISCO A. GONZÁLEZ REDONDO

De hecho, poco antes de que estallara la contienda ya le había sido concedido permiso por el Gobierno de la República para viajar a Europa y América «en misión cultural», con pasaporte dado en Madrid el 26 de junio de 1936, valedero por un $\mathrm{ann}^{\mathrm{j}^{72}}$. Ahora, finalizada la guerra, sería encargado de llevar a cabo una misión para incorporar los centros hispánicos de Argentina y Uruguay a la España Nacional y se preparaba para realizar una visita a esos países con el objetivo de conseguir su adhesión al nuevo régimen.

En una instancia del 19 de junio de 1939 (acompañada de una copia de la invitación de la Institución Cultural Española) dirigida a la Jefatura de los Servicios de Enseñanza Superior y Media del Ministerio de Educación Nacional, exponía ${ }^{73}$ :

Que antes de estallar el Glorioso Movimiento Nacional estaba invitado por la Institución Cultural Española de Buenos Aires para dar un cursillo de I2 lecciones en dicho Centro, sobre el tema «Curso breve de Aerodinámica». Estando autorizado para hacerlo la guerra interrumpió mi propósito. Recientemente la misma Institución Cultural Española de Buenos Aires me ha reiterado la invitación que yo estoy dispuesto a aceptar.

Por tanto, a v.E. Suplico que previo los trámites necesarios se sirva autorizarme para desplazarme a Buenos Aires, con objeto de explicar el cursillo mencionado.

En respuesta a la solicitud del Servicio Nacional de Enseñanza Superior y Media, el decano de la Facultad de Ciencias, Luis Bermejo, informaba favorablemente la propuesta de Palacios el 3 de julio, describiendo la situación del centro en aquellos momentos ${ }^{74}$ :

Debo manifestarle que la Sección de Física de la Facultad de Ciencias no cuenta con otro profesor numerario que el Dr. Julio Palacios Martínez para los trabajos académicos de la misma. Por otra parte, de la instancia del Sr. Palacios se deduce que el tiempo de su ausencia sería relativamente breve, todavía más para el trabajo en la Facultad por la época en que nos encontramos y que parece que dicho Sr. Catedrático desea utilizar. Y si a estas últimas circunstancias se suman el prestigio científico del Sr. Palacios y la conveniencia de extender hasta los españoles e hispanoamericanos del otro lado del Atlántico el influjo de nuestros profesores, como uno de los medios más eficaces de afianzar la influencia y el prestigio de la nueva España en el mundo; el Decano que suscribe entiende que puede accederse a lo solicitado.

Como cabía esperar, el Ministerio autorizaría el viaje el 22 de julio de $1939^{75}$ «vista la conveniencia del servicio que ha de realizar el citado profesor extendiendo hasta los españoles e hispanoamericanos del otro lado del Atlántico el influjo de nuestros profesores -uno de los medios más eficaces de afianzar la influencia y el prestigio de la nueva España en el mundo-».

Archivo Julio Palacios, Caja D2.

Expediente personal de Julio Palacios, AGA, legajo 32/I5052.

74 Expediente personal de Julio Palacios, AGA, legajo 32/15052.

75 Expediente personal de Julio Palacios, AGA, legajo $32 / 15052$. 
ENTRE JOSÉ CASTILLEJO Y JOSÉ M. a ALBAREDA: JULIO PALACIOS, EL «ÚLTIMO PRESIDENTE» DE LA JUNTA PARA AMPLIACIÓN DE ESTUDIOS, I939-I940 ROSARIO E. FERNÁNDEZ TERÁN Y FRANCISCO A. GONZÁLEZ REDONDO

Palacios salió hacia Buenos Aires el 9 de agosto de 1939. Tras realizar la tarea encomendada, el 4 de octubre preparaba su vuelta a España, a donde llegaría a finales de octubre, según manifestaba el 28 de ese mes el rector de la Universidad Central, Pío Zabala, en palabras recogidas en el Libro de Actas de la Junta de Gobierno: «Siendo felicitado por el Rector en nombre de la Junta, por su feliz llegada, así como de los éxitos tan lisonjeros obtenidos con motivo de las conferencias allí dadas» ${ }^{76}$. El propio Palacios hacía una valoración análoga de su viaje a Uruguay y Argentina ${ }^{77}$ :

Logrado esto [poner en marcha los centros de la antigua JAE], marché, acompañado de mi esposa, a Sudamérica con la misión de reanudar las relaciones con las Instituciones Culturales Españolas de Uruguay y Argentina, empresa difícil por la división que la guerra había producido en los dirigentes de dichas Instituciones. Sin embargó, conseguí un resultado plenamente satisfactorio porque, sin rozar la política, me limité a dar conferencias de carácter puramente científico, con lo que todos quedaron dispuestos a seguir prestando su apoyo a España, para fines culturales, apoyo que en aquellas circunstancias era más importante que antes.

Estaba previsto que mi misión continuase por las repúblicas hispánicas más importantes pero estalló la guerra en Europa y el temor de que quedasen cortadas las comunicaciones transatlánticas nos hizo regresar apresuradamente a España.

\section{La «misión rectora» de Palacios, ¿̇obra de la ILE?}

A su vuelta de Argentina Palacios siguió con las tareas de reorganización de los centros de la Junta. Así, el 8 de noviembre escribió a los directores de la Comisión de Adquisición de Material Científico, Centro de Estudios Históricos, Centro de Investigaciones Vinícolas, Jardín Botánico, Museo Antropológico, Centro de Estudios Filosóficos y Matemáticos, Museo Nacional de Ciencias Naturales, Instituto de Estudios Internacionales y Económicos, Instituto Cajal ${ }^{8}$ solicitándoles «para información de la Mesa [del Instituto] y poder resolverlos con mayor acierto», se sirviesen, «siempre que proponga ese Centro el nombramiento de personal afecto al mismo, indicar en qué estado se halla el propuesto respecto a su depuración» ${ }^{79}$.

Pero la realidad había cambiado profundamente. Durante la ausencia del físico aragonés, José Ibáñez Martín había sido nombrado ministro de Educación Nacional, y éste, con discreción, había estado preparando las nuevas reformas, que conducirían a la creación del csic, con la persona que debía jugar el papel que durante tantos años habían jugado José Castillejo/Santiago Ramón y Cajal en la

${ }^{76}$ «Sesión del 28 de octubre de 1939», Libro de Actas de la Junta de Gobierno de la Universidad de Madrid, p. i38. Archivo Histórico de la UCM.

77 Archivo Julio Palacios, Caja $\mathrm{D}_{7}$.

${ }_{78}$ En la lista no hacía falta incluir explícitamente al Instituto Nacional de Física y Química, pues, como se apuntaba antes, la dirección de este centro recaía en el propio Palacios desde el final de la guerra.

79 Archivo de la Residencia de Estudiantes, Caja 8530, Carpeta 5. 
ENTRE JOSÉ CASTILLEJO Y JOSÉ M. a ALBAREDA: JULIO PALACIOS, EL «ÚLTIMO PRESIDENTE» DE LA JUNTA PARA AMPLIACIÓN DE ESTUDIOS, I939-I940 ROSARIO E. FERNÁNDEZ TERÁN Y FRANCISCO A. GONZÁLEZ REDONDO

JAE, y que debía realizar la tarea de reconstrucción de las instituciones científicas que le estaba correspondiendo a Palacios como «último presidente» de la Junta: José M. ${ }^{a}$ Albareda Herrera.

De hecho, Pedro Laín describía con precisión la situación años antes de escribir su Descargo de conciencia de $1976^{80}$, al recordar que ${ }^{81}$ «todo parecía dispuesto para que a partir de 1939 fuese don Julio Palacios la figura rectora», dadas la «plena madurez de su formación científica, su nunca desfalleciente y siempre proclamada condición de católico y monárquico» e incluso su «estilo de patriota a la vieja usanza»; todo le hacía «más que idóneo en aquellos días para esa ardua función rectora». Sin embargo, seguía reconociendo Laín:

Circunstancias que ahora no son del caso -a las cuales, dicho sea en inciso, tal vez no fuera ajena la noble, invariable y amistosa fidelidad a sus antiguos compañeros de que antes hice mención- ${ }^{82}$ impidieron que se cumpliese tan prometedora posibilidad de su vida y le obligaran a iniciar una segunda etapa de su magisterio.

Esa fidelidad a los antiguos compañeros llevaría a conceptuaciones de Palacios como la que destacaba otro de sus discípulos y colaboradores tras la guerra, Leonardo Villena ${ }^{83}$ : «Con mi opinión sencilla y provinciana no comprendía que algunos le tacharan de izquierdoso cuando yo le veía como un señor de derechas, aunque con el talante liberal de los universitarios».

Pero no era sólo que se pretendiera presentarle como un «liberal», ni tan siquiera como el continuador de la JAE, sino que se le conceptuaría prácticamente como un «hombre de la ILE», esa «poderosa fuerza secreta» que había sido considerada culpable de la «tragedia de España» ${ }^{84}$, como se comprueba en los Informes preparatorios que había ido redactando Albareda y que pueden caracterizarse como de "anti-Palacios». Así, empezaba proponiendo al ministro ${ }^{85}$ que quedasen «sin efecto cuantos nombramientos, designaciones o encargos hayan podido hacerse antes de esta organización de la investigación científica». De este modo, una vez «delimitado y organizado el conjunto de los Centros, con las modificaciones que se estimen oportunas, se realizarán los nombramientos correspondientes». Y, en ese papel que estaba jugando Albareda, también apuntaba a Ibáñez Martín que ${ }^{86}$ :

so Laín Entralgo, P.: Descargo de conciencia, Barcelona, Círculo de Lectores, 1976 (2. ${ }^{a}$ ed., 2003).

8r Laín Entralgo, P.: «Discurso», en Solemne sesión necrológica en memoria del Excmo. Sr. D. Julio Palacios Martínez, I3 de mayo de 1970, Madrid, Real Academia de Ciencias, 1970, p. 687.

82 Laín había mencionado explícitamente a Blas Cabrera, Miguel Catalán, Arturo Duperier, etc.

83 Villena PARdo, L.: «Julio Palacios: labor didáctica, confinamiento y proyección internacional», Aula de Cultura Científica, Santander, Amigos de la Cultura Científica, n. ${ }^{\circ} 24$ (1985), p. I2. Puede verse, complementariamente, CAlleya DE PAlacios, E.: «Semblanza biográfico-científica de Julio Palacios», Aula de Cultura Científica, Santander, Amigos de la Cultura Científica, n. ${ }^{\circ} 22$ (1985).

${ }^{84}$ Pueden verse SUÑER: op. cit., 1937, y vv. AA.: op. cit., I940.

85 Archivo de la Residencia de Estudiantes, Caja 8548, Carpeta I.

${ }_{86}$ Archivo de la Residencia de Estudiantes, Caja 8548, Carpeta 3. 
ENTRE JOSÉ CASTILLEJO Y JOSÉ M. a ALBAREDA: JULIO PALACIOS, EL «ÚLTIMO PRESIDENTE» DE LA JUNTA PARA AMPLIACIÓN DE ESTUDIOS, I939-I940 ROSARIO E. FERNÁNDEZ TERÁN Y FRANCISCO A. GONZÁLEZ REDONDO

El dejar sin efecto los nombramientos, designaciones o encargos hechos, conviene, de una parte por lo indicado en $(6)^{87}$; ha de haber las modificaciones que se consideren mejoras efectivas, sin sentirse previamente sujetos a lo que la Junta [para Ampliación de Estudios] estableció; de otra parte, para que sea el Ministro, la única autoridad, la que haga las designaciones. No se trata de demoler: algunos nombramientos podrían confirmarse inmediatamente, pero por el Ministro, no por un Vicepresidente del Instituto de España.

Pero, sobre todo, en el escrito elevado a Ibáñez Martín sobre «los centros e Institutos de investigación antes de 1936 y en nuestros días» ${ }^{88}$, Albareda insistía en su ataque a la tarea de reorganización emprendida por Palacios, acusándole de que «lo acaecido actualmente en el Rockefeller [el Instituto Nacional de Física y Química], Museo de Ciencias Naturales, Seminario Matemático, etc.», todos ellos dependientes de Palacios, «ha rebasado a veces los límites de la política antinacional para oscilar entre lo grotesco y el área de las leyes penales». Este tipo de acusaciones, que podían llevar a Palacios ante los tribunales de justicia franquista, eran completados con «cargos» complementarios ${ }^{89}$ :

No se ha encauzado nada, y cuando se ha intentado mejor hubiera sido dejarlo: el Rockefeller [INFQ], que se quiso constituir inmediatamente [por su Director, Julio Palacios], era a base de institucionistas de los más altos grados, personas venidas del extranjero al Madrid rojo, etcétera. La Institución [Libre de Enseñanza] en el poder no hubiese sabido hacer más. Por desconocimiento y desidia, se daba la absurda sensación de que los rojos son necesarios para hacer marchar la alta cultura, la investigación y las relaciones con el extranjero.

Estas declaraciones contra Palacios, con graves acusaciones de índole política, en las que personificaba al físico aragonés como continuador de la obra de la ILE, las completaba ante el ministro con otras consideraciones de tipo más académicocientíficas: "Así se da el caso de un Instituto Nacional de Física y Química, cuya existencia ha sido indiferente al desarrollo industrial del país, pues la Técnica estaba allí proscrita». Y continuaba: «Todas las figuras españolas de Química técnica han sido desdeñadas o maltratadas por la Junta. Y sin embargo, la Técnica es un magnífico control de eficacia, porque no admite el parasitismo del camelo».

En suma, la situación que dibujaba Albareda al Ministerio contra la tarea realizada por Palacios como continuación de la obra de la JAE (o, lo que era peor, de la ILE) era demoledora ${ }^{90}$ : "Hoy existe un Patronato en el Rockefeller, de carácter oficial, otro oficioso en el Museo de Ciencias Naturales, en otros Centros hay un solo Director, hasta existe una junta para ver a qué revistas extranjeras nos suscribimos».

87 Este apartado justificaba el objetivo resumido en la primera frase con la que se inicia: «Hay que modificar en todo lo que convenga la organización de Centros».

88 Archivo de la Residencia de Estudiantes, Caja 8548, Carpeta 5.

89 Archivo de la Residencia de Estudiantes, Caja 8548, Carpeta 8. Este informe de Albareda apareció citado parcialmente en SÁNchez Ron: op. cit., I999. También se analiza en MALET: op. cit., 2008.

90 Archivo de la Residencia de Estudiantes, Caja 8548, Carpeta 8. 
ENTRE JOSÉ CASTILLEJO Y JOSÉ M. a ALBAREDA: JULIO PALACIOS, EL «ÚLTIMO PRESIDENTE» DE LA JUNTA PARA AMPLIACIÓN DE ESTUDIOS, I939-I940 ROSARIO E. FERNÁNDEZ TERÁN Y FRANCISCO A. GONZÁLEZ REDONDO

Y concluía: «Casi todos los centros dependen de la mesa del Instituto de España. Y en realidad todo está muerto».

Pero, en esos momentos, se generalizaban ya los ataques contra Palacios y su obra de reconstrucción de los centros de la JAE y la FNICER manteniendo en sus puestos a las personas de valía que no habían abandonado España, y prescindiendo de los advenedizos. Así, uno de éstos, su antiguo colaborador en la Sección de Rayos X del Rockefeller, Octavio Foz Gazulla, le reiteraría por carta las acusaciones que había presentado ante la justicia franquista contra el personal del Instituto Nacional de Física y Química, indignando a Palacios, y que llevaría a la cárcel a varios de ellos ${ }^{91}$ :

Sus protestas de inocencia serán inútiles mientras los hechos contradigan sus palabras; más fuerte que éstas habla, p. ej. la presencia en el Instituto de los Ciriacos, Sanchos, Herreros, Garridos, Velayos, etc., dispuestos a actuar de corifeos tan pronto como V. tenga a bien atropellar a una persona de derechas. Que, por otra parte, sea V. incapaz de comprender mi actitud heroica, no es extraño, dada su estrecha convivencia con los acomodaticios enchufistas de la Institución [Libre de Enseñanza].

\section{Hacia el final definitivo de la JAE: el CSIC}

El 24 de noviembre de 1939 se publicaba en el $B O E$ la Ley por la que se creaba el Consejo Superior de Investigaciones Científicas ${ }^{92}$, la nueva institución franquista «que tendrá por finalidad fomentar, orientar y coordinar la investigación científica nacional» y que reducía el Instituto de España a mero enlace de las reales Academias.

De acuerdo con el artículo $6 .^{\circ}$ de la Ley, se reconocía implícitamente la labor de continuidad realizada por Palacios al disponer que «todos los Centros dependientes de la disuelta Junta para Ampliación de Estudios e Investigaciones Cientificas, de la Fundación de Investigaciones Cientificas y Ensayos de Reforma», así como «los creados por el Instituto de España, pasarán a depender del Consejo Superior de Investigaciones Científicas». Quedaban ligados también al Consejo los Centros investigadores del Ministerio, no vinculados a la Universidad.

Según el artículo $7 .^{\circ}$, todos los centros mencionados en el artículo anterior «y los que deban crearse para atender debidamente la elevada misión científica del Consejo, se ordenarán en Patronatos e Institutos» y su «número, estructura, funcionamiento y relaciones con otros Centros oficiales o privados» quedarían determinados por un futuro Reglamento. Por otro lado, el artículo io disponía que «los bienes de todas clases pertenecientes a la disuelta Junta para Ampliación de Estudios y a la Fundación Nacional de Investigaciones Científicas» pasarían al Consejo Superior de Investigaciones Científicas «que asume las obligaciones antes

${ }_{91}$ Archivo Julio Palacios, Caja $\mathrm{D}_{3}$.

${ }_{92} B O E$, n. $^{\circ} 332,28$ de noviembre de I939, pp. 6668-667I. 
ENTRE JOSÉ CASTILLEJO Y JOSÉ M. a ALBAREDA: JULIO PALACIOS, EL «ÚLTIMO PRESIDENTE» DE LA JUNTA PARA AMPLIACIÓN DE ESTUDIOS, I939-I940 ROSARIO E. FERNÁNDEZ TERÁN Y FRANCISCO A. GONZÁLEZ REDONDO

encomendadas a aquellos organismos». Y, finalmente, el artículo i2 recogía que quedaban «sin efecto cuantos nombramientos, designaciones o encargos hayan podido hacerse antes de esta organización de la investigación científica».

Palacios, desconociendo absolutamente el papel que llevaba jugando Albareda desde meses antes, pero enterado de la nueva etapa (en esos momentos plasmada únicamente sobre el papel en el $B O E$ ) que se estaba pensando iniciar desde el Ministerio, escribía con membrete del Instituto Nacional de Física y Química ofreciéndose él mismo a continuar la tarea «rectora» como un nuevo Castillejo ${ }^{93}$ :

Mucho más importante que la elección de Vicepresidentes y Vocales del Consejo Superior de Investigaciones es el acierto en la elección de Secretario. Los primeros llevarán cumplidamente su cometido si son personas de prestigio y recta intención. El segundo ha de reunir requisitos nada fáciles de encontrar en una sola persona:

I. ${ }^{\circ}$ Ha de imponerse por la autoridad que dimane de su cultura, de su prudencia $\mathrm{y}$ de sus reiterados aciertos.

2. ${ }^{\circ}$ Ha de tener la abnegación de dedicar toda su actividad al nuevo Consejo, renunciando a toda gloria y provecho que no procedan del ejercicio de su cargo.

$3 .^{\circ}$ Ha de desempeñar, ante todo, la ingrata misión de servir de intermediario entre la Administración y los investigadores, evitando que estos pierdan tiempo en visitas y gestiones y asegurándoles la tranquila permanencia en sus puestos, para lo cual habrá de defenderles hábilmente contra envidias y maniobras mal intencionadas.

$4 .^{\circ} \mathrm{Ha}$ de elegir un personal administrativo eficaz, que lleve los asuntos al día, de tal modo que se reduzca al mínimo la labor burocrática de los centros de investigación.

Pero Palacios llegaba tarde. En enero de 1940 el Consejo Ejecutivo, órgano general del gobierno del csic, quedaba constituido por el ministro de Educación Nacional, José Ibáñez Martín, como presidente; José Asín Palacios, como vicepresidente primero; Antonio de Gregorio Rocasolano, como vicepresidente segundo; y José M. Torroja Miret, como interventor general94. Y, sobre todo, aunque no aparecería publicado en el $B O E$ hasta el 24 de ese mes de enero, el 30 de diciembre de 1939 se había firmado el Decreto nombrando secretario del CSIC a José M. ${ }^{a}$ Albareda ${ }^{95}$.

Aunque se trataba aún de reformas «sobre el papel», pendientes de su implementación, y los antiguos centros de la JAE y la FNICER seguían reorganizándose en las condiciones establecidas por Palacios, el io de febrero de I940 se firmaba el Decreto ${ }^{96}$ «regulando el funcionamiento» del csic, detallando los Patronatos en los que se agruparían los nuevos centros de investigación. Ese mismo día

93 Aunque en la carta no aparece firma ni fecha, en ella se reconoce la letra de Julio Palacios. Archivo de la Residencia de Estudiantes.

$94 B O E$, n. ${ }^{\circ}$ 3I, 3I de enero de I94O, p. 8IO.

$95 B O E$, n. $^{\circ} 24,24$ de enero de 1940, p. 6II.

$96 B O E$, n. $^{\circ} 48,17$ de febrero de 1940 , pp. I2OI-I203. Este reglamento se recoge también en Estructura y norma de la Investigación Nacional. (Texto de la Ley, Reglamento y Disposiciones complementarias del Consejo Superior de Investigaciones Cientificas), Madrid, csic, 1940. 
ENTRE JOSÉ CASTILLEJO Y JOSÉ M. a ALBAREDA: JULIO PALACIOS, EL «ÚLTIMO PRESIDENTE» DE LA JUNTA PARA AMPLIACIÓN DE ESTUDIOS, I939-I940 ROSARIO E. FERNÁNDEZ TERÁN Y FRANCISCO A. GONZÁLEZ REDONDO

se publicaba un segundo Decreto ${ }^{97}$ nombrando a los vocales del csic. Entre los «representantes de las Universidades» sí se encontraba Julio Palacios, pero era simplemente uno más en una amplia lista de personalidades tales como Enrique Suñer Ordóñez, Antonio de Gregorio Rocasolano, Luis Bermejo Vida, Emilio Jimeno Gil, Antonio Rius Miró, Fernando Enríquez de Salamanca, José Casares Gil, Ángel González Palencia, etc.

En suma, como confesaba Palacios en una carta al ministro Ibáñez Martín enviada el 6 de abril de $1940^{98}$.

Al despedirme de V. después de la última y larga entrevista que tuvo la amabilidad de concederme, pronunció $\mathrm{V}$. una frase que me impresionó hondamente. Me dijo: «recuerde V. que ahora gobernamos sus amigos». Confieso que, desde mi regreso de Buenos Aires, han sido tantos los desaires y disgustos que he sufrido, que hubo momentos en que pasó por mi mente la idea de que ocurría todo lo contrario. Pero sus palabras han desvanecido todo recelo y estoy persuadido de que, lo que me sucede y lo que ocurre en otros muchos casos, se debe a la ruin maniobra de gente que se mueve con fines egoístas o, lo que es peor, a nuestros enemigos, que tratan hábilmente de entorpecer la obra de reconstrucción de España a la que los buenos españoles deseamos dedicarnos con todo empeño.

En esos momentos, a Palacios solamente le quedaba una carta para seguir jugando: el control administrativo-económico de los centros de la JAE y la FNICER, así como los pagos de las nóminas del personal desde el Instituto de España. De hecho, tendría el tiempo justo para dar las órdenes de pago hasta el mes de mayo (incluido) de $1940^{99}$, antes de que el 28 de abril se publicase la Orden firmada por Ibáñez Martín el I8 ${ }^{100}$ exigiéndole que, «en el plazo de ocho días», traspasase «los servicios, locales, efectos y documentación procedentes de las extinguidas Juntas para Ampliación de Estudios y Fundación Nacional de Investigaciones Cientificas». Así mismo, ordenaba que «en el plazo de quince días el Instituto de España» hiciera «una liquidación provisional de su situación económica, entregando el saldo que exista actualmente» $y$, «sin perjuicio de esta liquidación provisional, en el plazo de dos meses presentará las cuentas de su gestión económica para su correspondiente aprobación».

Aunque el ministro Ibáñez Martín le contestaría unas semanas después que ${ }^{\text {ror }}$ «he leído con todo detenimiento su larga e interesante carta de fecha 6 del corriente, y tenga Vd. la seguridad de que he de tener en cuenta, en cuanto sea posible, sus informaciones», durante esos dos meses concedidos se completaría

$B O E$, n. $^{\circ} 48$, I7 de febrero de I94O, pp. I203-I204.

Archivo Julio Palacios, Caja Di4.

99 Archivo Central del csic, Libro 279 (antiguo I63), AGA.

1oo Orden de I8 de abril de 1940 «disponiendo que el Instituto de España traspase al Consejo Superior de Investigaciones Científicas todos los servicios de las disueltas Junta para Ampliación de Estudios y Fundación Nacional de Investigaciones Científicas», BOE, n. ${ }^{\circ}$ II9, 28 de abril de 1940, p. 2898.

ror Carta de José Ibáñez Martín del 6 de mayo de 1940. Archivo Julio Palacios, Caja Diz. 
ENTRE JOSÉ CASTILLEJO Y JOSÉ M. a ALBAREDA: JULIO PALACIOS, EL «ÚLTIMO PRESIDENTE» DE LA JUNTA PARA AMPLIACIÓN DE ESTUDIOS, I939-I940 ROSARIO E. FERNÁNDEZ TERÁN Y FRANCISCO A. GONZÁLEZ REDONDO

la marginación de Palacios, tal como constataba, por ejemplo, su antiguo discípulo y entonces ya catedrático en la Universidad de La Laguna, Luis Brú, el 7 de junio de $1940^{\text {102: }}$

Leo con verdadera sorpresa, y no poca desilusión, que su nombre falta en organismos y Juntas en las que debía figurar a la cabeza de todos. Esto me hace pensar que el temporal que empezó, precisamente, por estos días hace un año, no se ha calmado todavía. Peor que peor para los que no saben comprender o se dejan guiar por quienes no debieran. Lo lamentable es que quien sale perdiendo es nuestra patria [...].

Finalmente, el 28 de octubre de 1940, el «Generalísimo» Franco presidiría el acto de inauguración oficial del csic. La Junta para Ampliación de Estudios y la Fundación Nacional para Investigaciones Científicas, ahora sí, pasaban a la historia. Y la tarea realizada por su «último presidente», Julio Palacios, también.

\section{Consideraciones finales}

Monárquico militante, reintegrado en las reuniones de antiguos miembros de Acción Española y Renovación Española, el Régimen franquista fue apartando a Palacios de todos sus puestos de dirección mientras le buscaba una salida. En enero de 1944, atendiendo una invitación del Instituto Portugués para Alta Cultura, el todavía respetado Palacios es enviado a Portugal en misión cultural, en un intento de destruir la «leyenda negra» que pesaba sobre ambos países por su supuesta incapacidad para la investigación científica. Pero en marzo de 1944 se pondría punto y final a su colaboración en la tarea de reconstrucción nacional de la que había ido siendo apartado tras su vuelta de Argentina.

Efectivamente, en unos momentos en los que la derrota de Hitler en la Segunda Guerra Mundial se avizoraba como inevitable, don Juan de Borbón comenzaba a mover sus fichas confiando en una restauración de la Monarquía en el país, y hacía público su llamamiento desde Suiza a los españoles. Palacios, que estaba a punto de leer su discurso de ingreso en la Real Academia Nacional de Medicina, firmaba un manifiesto de adhesión a don Juan junto con otros intelectuales monárquicos (Alfonso García Valdecasas, Juan José López Ibor, Jesús Pavón, etc.). De manera fulminante, se le desterró y confinó en Almansa (Albacete) ${ }^{\mathrm{roz}}$ y se le destituyó de los cargos que le quedaban (por ejemplo, el de vicerrector de la Universidad de Madrid, el 23 de marzo) $)^{104}$.

Levantado el confinamiento y readmitido en la Universidad a finales de 1944, su vida ${ }^{\text {105 }}$ se dirigiría hacia un semiexilio en Lisboa, consentido en 1947 por las

${ }_{102}$ Archivo Julio Palacios, Caja $\mathrm{D}_{3}$.

${ }_{103}$ Puede verse Pérez Mateos, J. A.: Los confinados. Relato vivo de los desterrados, Barcelona, Plaza \& Janés, 1976, pp. I66-173.

104 AGA, Sección Educación, legajo 32-15052.

ros Sobre estos años en la vida de Palacios pueden consultarse: Villena Pardo: 1985, op. cit. y Calleya de Palacios: 1985 , op. cit. 
autoridades franquistas, y que agradecerían notablemente en Portugal, donde retomaría su extraordinaria labor docente, escribiría los libros de texto de Física más estudiados tanto en España como en Portugal y pondría en marcha significativos grupos de investigación: Facultad de Ciencias de Lisboa, Laboratorio de Radiaciones del Instituto de Oncología, Laboratorio de Física Atómica de la Comisión de Energía Nuclear, etc.

En efecto, muchos aspectos de la vida de Julio Palacios son ciertamente relevantes para la Historia de la Educación en España. Entre ellos podría destacarse uno especialmente singular: el papel del catedrático aragonés, pactado por el generalísimo Franco y don Juan de Borbón, como tutor de los estudios del entonces príncipe Juan Carlos. Será un tema que trataremos en un futuro trabajo. 